\title{
Numerical modelling of 2003 summer forest fire impacts on air quality over Portugal
}

\author{
A. I. Miranda ${ }^{1}$, V. Martins ${ }^{1}$, M. Schaap ${ }^{2}$, R. San José ${ }^{3}$, J. L. Perez ${ }^{3}$, \\ A. Monteiro ${ }^{1}$, C. Borrego ${ }^{1} \&$ E. Sá ${ }^{1}$ \\ ${ }^{I}$ CESAM \& Department of Environment and Planning, \\ University of Aveiro, Portugal \\ ${ }^{2}$ TNO, Department of Air Quality and Climate, The Netherlands \\ ${ }^{3}$ Universidad Politécnica de Madrid, Campus de Montegancedo, Spain
}

\begin{abstract}
In 2003 Portugal faced the worst fire season ever recorded. The main purpose of this work is to evaluate the effects of the 2003 forest fires on the air quality, applying four numerical modelling systems (LOTOS-EUROS, MM5-CMAQ, WRF/chem and MM5-CHIMERE), and to compare their results with air quality data from several monitoring stations in Portugal. Forest fire emissions have been calculated taking into account the most suitable parameters for Portuguese forest/fire characteristics and the area burned by each forest fire. They were added to the anthropogenic and biogenic gridded emissions, according to the fire location and assuming a uniform fire spread and injection into the mixing layer. Simulations were performed during August 2003 regarding gaseous and particulate matter pollutants. To better evaluate the impact of forest fire emission on the air quality, a baseline simulation was performed, including the "conventional" emissions, along with a forest fire simulation, which also considered emissions from forest fires. Modelling hourly results, namely particulate matter $(\mathrm{PM})$ and ozone $\left(\mathrm{O}_{3}\right)$ concentration, values have been compared to measurement data at several monitoring locations. In general, the different modelling systems show a good performance, which improves when forest fire emissions are considered, particularly for the PM concentrations. The influence of the forest fire emissions in $\mathrm{O}_{3}$ formation is not so evident and needs more attention. The evaluation of the impact of forest fires on the air quality should be included in air quality assessment procedures, specifically in areas that
\end{abstract}


are often affected by forest fires, such as south Europe, and air quality modelling systems can be important tools to achieve this goal.

Keywords: air quality modelling, forest fires, atmospheric emissions, particulate matter, ozone.

\section{Introduction}

Smoke has to be considered as one of the several disturbing effects of forest fires; it contains important amounts of carbon monoxide and dioxide ( $\mathrm{CO}$ and $\left.\mathrm{CO}_{2}\right)$, methane $\left(\mathrm{CH}_{4}\right)$, nitrogen oxides $\left(\mathrm{NO}_{\mathrm{x}}\right)$, ammonia $\left(\mathrm{NH}_{3}\right)$, particulate matter (PM), particles with a mean diameter less than $2.5 \mu \mathrm{m}$ (PM2.5) and particles with a mean diameter less than $10 \mu \mathrm{m}$ (PM10), non-methane hydrocarbons (NMHC) and other chemical compounds. The effects of these emissions are felt at different levels: from the contribution to the greenhouse effect $[1,2]$ to the occurrence of local atmospheric pollution episodes, including high $\mathrm{O}_{3}$ concentrations at medium distances from the emission sources [3]. Moreover, impacts on air quality and human health can be significant, as individuals and populations are exposed to hazardous air pollutants [4].

To understand and to evaluate forest fire effects on air quality, several factors should be analysed and comprehensively integrated, namely: fire progression, fire emissions, atmospheric flow, smoke dispersion and chemical transformation. There are several numerical modelling systems in development, some of them already available, aiming to estimate the dispersion of smoke from forest fires and their impact on the air quality. However, the majority of these systems do not include all the mentioned factors. Crucial in all systems is the quality of the forest fire emission estimates. Recently, quite a few works used remote sensing data to estimate emissions from wild land fires and to examine the impacts of specific fire events on regional and urban air quality [5, 6]. Alternatively, detailed information on burnt area, fuel loads, vegetation type, burning efficiency and emission factors can be used to estimate forest fire emissions, when available (e.g. [7]). Both approaches are nowadays an ongoing research topic.

The main purpose of this work is to evaluate the effect of forest fires emissions on the air quality applying four numerical modelling systems (LOTOS-EUROS, MM5-CMAQ, WRF/chem and MM5-CHIMERE) along a particular fire season, and to compare their results with air quality data from several monitoring stations in Portugal.

\section{The modelling systems}

The air quality modelling applications were performed using four different air quality modelling systems: MM5-CMAQ; MM5-CHIMERE; LOTOS-EUROS; and $\mathrm{WRF} / \mathrm{chem}$. All are 3D chemical transport models aimed to simulate air pollution in the lower troposphere.

Both CMAQ and CHIMERE were driven by the meteorological mesoscale model MM5. The MM5 model is a non-hydrostatic mesoscale meteorological 
model $[8,9]$ that is widely used around the world for meteorological research and also for operational meteorological use. It is capable of producing 3D wind, temperature, humidity and other important meteorological parameters and variables during simulations of several hours and days. It is based on a nestedgrid primitive-equation model, which uses a terrain following sigma vertical coordinates. The LOTOS-EUROS model used as meteorological information data provided by the Free University of Berlin, which are based on a diagnostic meteorological model.

The CMAQ model [10] is a Comprehensive Air Quality Model which simulates the chemical transformations and the dispersion of the pollutants in a 3D domain. CMAQ model is structured in a full modular way. The different configurations should be consistent with those prepared for the MM5 meteorological simulations. Different applications of the MM5-CMAQ air quality modelling system have been performed during the last decade [11].

CHIMERE was specifically developed for simulating gas-phase chemistry, aerosol formation, transport and deposition at European and urban scales. The model simulates the concentration of 44 gaseous species and 6 aerosol chemical compounds. The gas-phase chemistry scheme, derived from the original complete mechanism MELCHIOR, has been extended to include sulphur aqueous chemistry, secondary organic chemistry and heterogeneous chemistry. The aerosol model accounts for both inorganic and organic species, of primary or secondary origin. MM5-CHIMERE has been applied and tested several times for the Portuguese conditions [12].

The LOTOS-EUROS model includes the $\mathrm{O}_{3}$ chemistry using a modified Carbon-Bond Mechanism 4 (CBM4) mechanism. The model incorporates primary (combustion) particles, sea salt and secondary inorganic aerosols. In the vertical the model has 4 layers up to the 3,500 meters following the dynamic mixing layer approach. The LOTOS-EUROS system has been used in several applications showing good agreement between the observed and the modelled data $[13,14]$.

$\mathrm{WRF} / \mathrm{chem}$ is an online multiscale air pollution prediction system based on the Weather Research and Forecasting (WRF) model, which is coupled with different chemical mechanisms. Biogenic and anthropogenic emissions, deposition, convective and turbulent chemical transport, photolysis, and advective chemical transport are all treated simultaneously with the meteorology. $\mathrm{WRF} / \mathrm{chem}$ is fully consistent since all transport is done by the meteorological model with the same vertical and horizontal coordinates (no horizontal and vertical interpolation), the same physics parameterization for subgrid scale transport and no interpolation in time. It is capable to simulate chemistry and aerosols from cloud scales to regional scales. It includes different aerosol modules in model approach, sectional approach and mass only from GOCART modelling system. The photolysis packages are all coupled to aerosols and hydrometeors. It includes 4D-VAR chemical data assimilation. WRF/chem has been developed by NOAA with contributions from NCAR, PNNL, EPA, and university scientists [15]. 


\section{Case study}

Each summer season wild land forest fires burn a considerable area of south European landscape. Summer 2003 was one of the most severe fire seasons experienced during the last decades in Southern Europe and, due to persistent extreme fire conditions, Portugal suffered the worst forest fire season that the country has faced in the last 23 years, with a total area burned of almost 5 times the average [16]. There were reports of more than one thousand people needing medical assistance due to smoke intoxications, burns and wounds from forest fires in Portugal [16]. Satellite images, like the one shown in Figure 1, and air pollutants concentration values measured by the Portuguese air quality monitoring network, highlighted the impact of forest fire emissions [17].

Large forest fires (defined by the Portuguese Authorities as fires greater than 100 ha) are responsible for the majority of the area burned in Portugal. In 2003 the large fires burned $96 \%$ of total area burned besides representing approximately only $1 \%$ of the total occurrences. Forest fire emissions were estimated for every large forest fire occurred in this 2003 fire season, based on the following equation.

$$
E_{i}=E F_{i} \times \beta \times B \times A
$$

where: $E_{i}$ - emission of compound i (g);EF - compound i emission factor $\left(\mathrm{g} \cdot \mathrm{kg}^{-1}\right) ; \beta$ - burning efficiency; $B$ - fuel load $\left(\mathrm{kg} \cdot \mathrm{m}^{-2}\right) ; A-$ area burned $\left(\mathrm{m}^{2}\right)$.

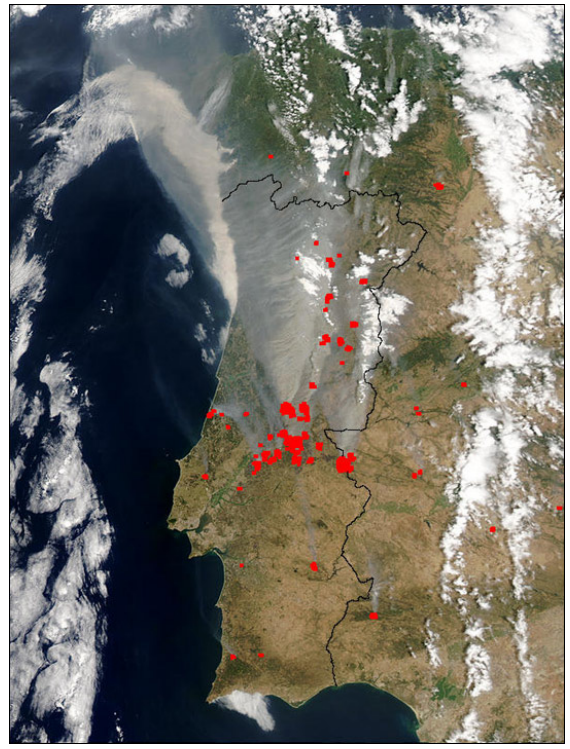

a)

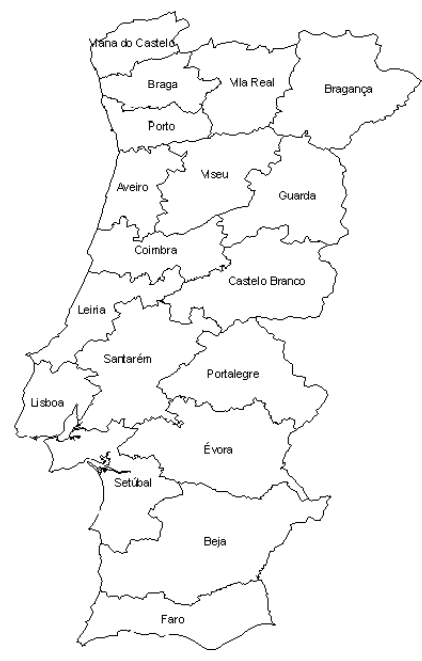

b)

Figure 1: $\quad$ Portuguese territory satellite image, 2003, August $3^{\text {rd }}$ (a); Districts over Portugal (b). 
Specific values for Portugal were selected based on data from the National Forest Inventory about the characteristics of the consumed forest type and shrubs. Furthermore, fire data like starting location and ignition time and area burned were collected from the National Forest Fires Inventory. The applied methodology has two components: (i) description of vegetation type, in terms of fuel load and combustion efficiency; and (ii) selection of the most adequate emission factors.

Forest fire emission values were added to the anthropogenic and biogenic gridded emissions, according to the fire location and assuming a uniform fire spread and injection into the mixing layer. Simulations with the four modelling systems were performed along August 2003 regarding gaseous and particulate matter pollutants. A baseline simulation (BS) was performed, including "conventional" emissions, and a forest fire simulation (FS), which also considered emissions from large forest fires.

The systems were firstly applied at the European scale and then over Portugal, using the same physics and a one-way nesting technique, and using the boundary conditions obtained from the coarser domain simulations. Table 1 lists the main characteristics of the air quality modelling systems applications.

For the European scale simulations, all systems used the emission inventory from the Netherlands Organisation for Applied Scientific Research (TNO), with the exception of CHIMERE that used the EMEP Program (Co-operative Programme for Monitoring and Evaluation of the Long-range Transmission of

Table 1: Main characteristics of the air quality modelling systems application.

\begin{tabular}{|c|c|c|c|c|}
\hline Parameter & LOTOS-EUROS & $\begin{array}{l}\text { MM5- } \\
\text { CMAQ }\end{array}$ & WRF/chem & MM5-CHIMERE \\
\hline $\begin{array}{l}\text { Boundary } \\
\text { conditions }\end{array}$ & $\begin{array}{c}\text { Logan } \\
\text { climatological } \\
\text { datasets; } \\
\text { LOTOS-EUROS } \\
\text { European } \\
\text { simulation }\left(0.5^{\circ} \mathrm{x}\right. \\
\left.0.25^{\circ} \text { resolution }\right)\end{array}$ & $\begin{array}{c}\text { MM5- } \\
\text { CMAQ } \\
\text { European } \\
\text { simulation } \\
\text { (50 km } \\
\text { resolution) }\end{array}$ & $\begin{array}{c}\text { WRF/chem } \\
\text { European } \\
\text { simulation }(50 \mathrm{~km} \\
\text { resolution) }\end{array}$ & $\begin{array}{c}\text { GOCART } \\
\text { climatological } \\
\text { models; MM5- } \\
\text { CHIMERE } \\
\text { European } \\
\text { simulation (50x50 } \\
\mathrm{km}^{2} \text { resolution) }\end{array}$ \\
\hline Emissions & TNO inventory & $\begin{array}{c}\text { TNO } \\
\text { inventory }\end{array}$ & TNO inventory & $\begin{array}{l}\text { EMEP and } \\
\text { Portuguese } \\
\text { inventory }\end{array}$ \\
\hline $\begin{array}{l}\text { Vertical } \\
\text { structure }\end{array}$ & $\begin{array}{l}4 \text { layers (up to } \\
3,000 \mathrm{~m} \text { ) }\end{array}$ & $\begin{array}{c}23 \text { layers (up } \\
\text { to } 10,000 \\
\mathrm{~Pa})\end{array}$ & $\begin{array}{c}23 \text { layers (up to } \\
10,000 \mathrm{~Pa} \text { ) }\end{array}$ & $\begin{array}{c}8 \text { layers (up to } \\
3,500 \mathrm{~m} \text { ) }\end{array}$ \\
\hline $\begin{array}{l}\text { Chemical } \\
\text { mechanism }\end{array}$ & CBM-IV & $\mathrm{cb} 05-\mathrm{ae} 4$ & cbmz_mosaic_4bins & MELCHIOR \\
\hline $\begin{array}{l}\text { Horizontal } \\
\text { grid } \\
\text { resolution } \\
\left(\mathrm{km}^{2}\right)\end{array}$ & $0.25^{\circ} \times 0.125^{\circ}$ & $\begin{array}{c}16.6 \times 16.6 \\
\mathrm{~km}^{2}\end{array}$ & $16.6 \times 16.6 \mathrm{~km}^{2}$ & $10 \times 10 \mathrm{~km}^{2}$ \\
\hline
\end{tabular}


Air Pollutants in Europe) emission inventory. For the Portuguese domain data from the most updated annual emission inventory (2003) developed by the Portuguese Agency for the Environment was used in case of the MM5CHIMERE. Time disaggregation was obtained by the application of monthly, weekly and hourly profiles from the University of Stuttgart.

\section{Results}

Hourly modelling results were compared to monitored air quality data acquired at different background air quality stations. Air quality data were available at 13 of the 18 districts in Portugal (districts identification is depicted in Figure 1b). Most of the stations are located near the major conurbations at the west coast of the country, most notably Lisbon and Porto.

Some statistical parameters were estimated to better assess the simulation results, namely the root mean square error (RMSE), the systematic error (BIAS), and the correlation coefficient (r) [18]. Aiming to have a comparative picture of the modelling systems skills Figure 2 presents the RMSE, the BIAS and the r, for PM10 and $\mathrm{O}_{3}$, averaged for each district, and considering the forest fire emissions.
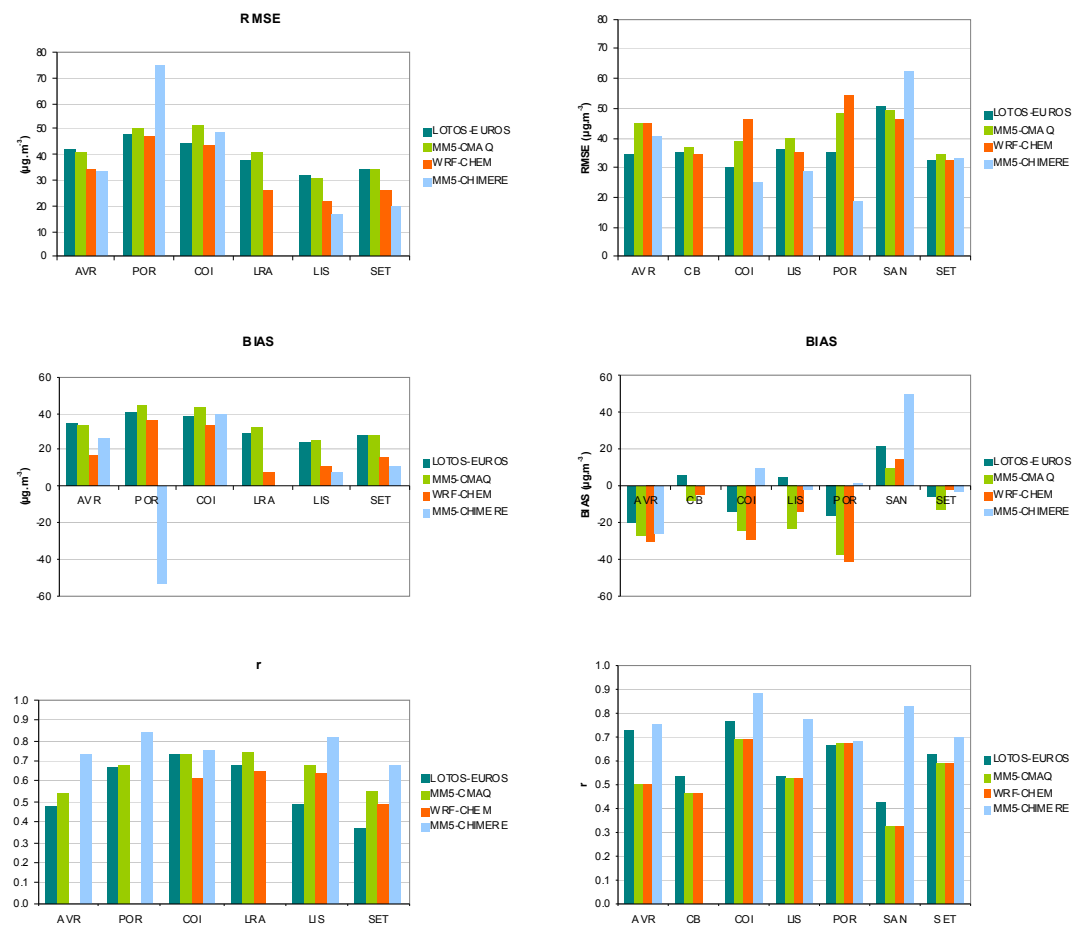

Figure 2: Averaged statistical indicators (RMSE, BIAS and r) concerning PM10 and $\mathrm{O}_{3}$ for 2003, August, by district. 


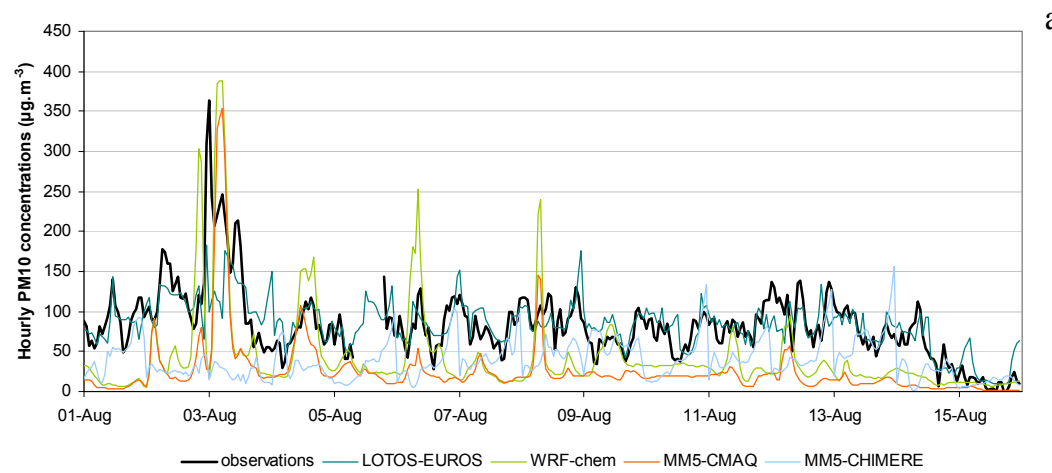

$\mathrm{a}$

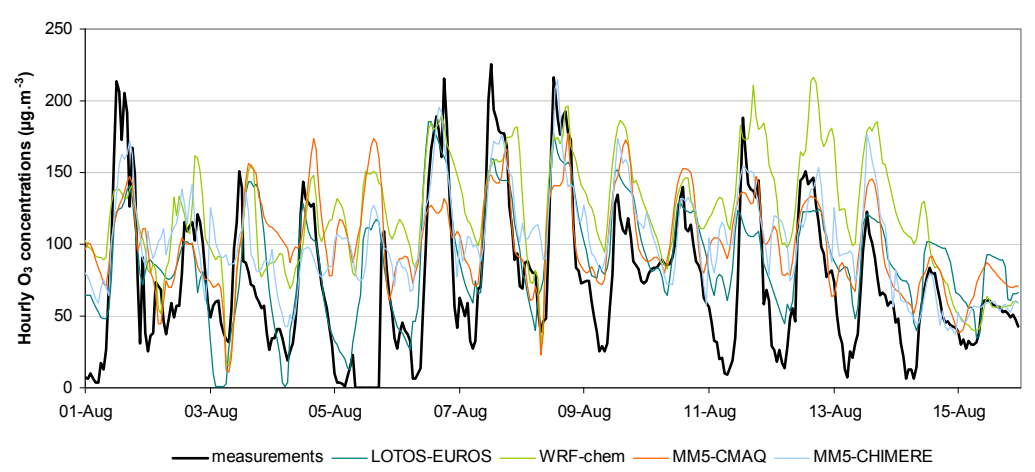

Figure 3: Hourly concentration values for PM10 (a) and $\mathrm{O}_{3}$ (b), between the $1^{\text {st }}$ and the $15^{\text {th }}$ August 2003 at IGC station.

In general, there is not a significant difference among the models results. For PM10, the MM5-CHIMERE modelling system has low skills at Porto district results, with a higher RMSE and a negative BIAS, indicating an overestimation of PM10. That's the only overestimation for all the models and districts. Excluding Porto results, the RMSE varies between 15 and $50 \mu \mathrm{g} . \mathrm{m}^{-3}$ and the BIAS between 5 and $40 \mu \mathrm{g} \cdot \mathrm{m}^{-3}$. The correlation coefficient is generally higher for MM5-CHIMERE and goes from 0.35 to 0.8 .

Regarding $\mathrm{O}_{3}$, the modelling systems tend to overestimate concentrations with a negative BIAS for almost all the districts and models. The RMSE vary between 20 and $60 \mu \mathrm{g} . \mathrm{m}^{-3}$ and the correlation coefficient between 0.3 and 0.9 .

Aiming to complement the statistical analysis Figure 3 shows the hourly timeseries for PM10 and $\mathrm{O}_{3}$ based on models results and measurements in a particular monitoring station - "Instituto Geofísico de Coimbra (IGC)". This monitoring station was selected because it is located in the central part of Portugal, which was one of the most affected ones by 2003 August forest fires. Data are presented for the first two weeks of August that were the most critical ones in terms of fire activity along this 2003 fire season. 
Concerning PM10 and for the selected period, LOTOS-EUROS and MM5CHIMERE systems tend to underestimate the measured peak PM10 values, namely at the $2^{\text {nd }}$ and $3^{\text {rd }}$ of August, when the fire activity was higher. MM5CMAQ and WRF/chem were able to capture these particular peaks of PM10 that happened at the beginning of August. For the other days LOTOS-EUROS is the modelling system that better follows the measured values.

For $\mathrm{O}_{3}$ the overestimation trend is confirmed. All the modelling systems tend to provide higher concentration values than the measured ones. Only when

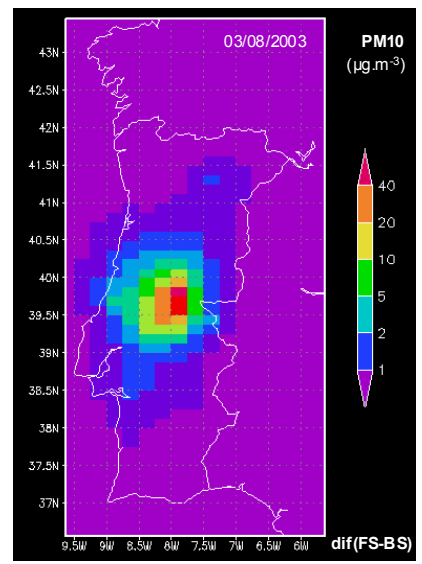

LOTOS-EUROS

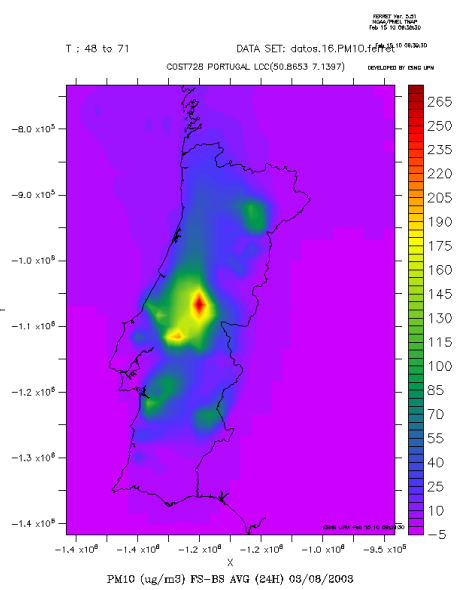

$\mathrm{WRF} / \mathrm{chem}$

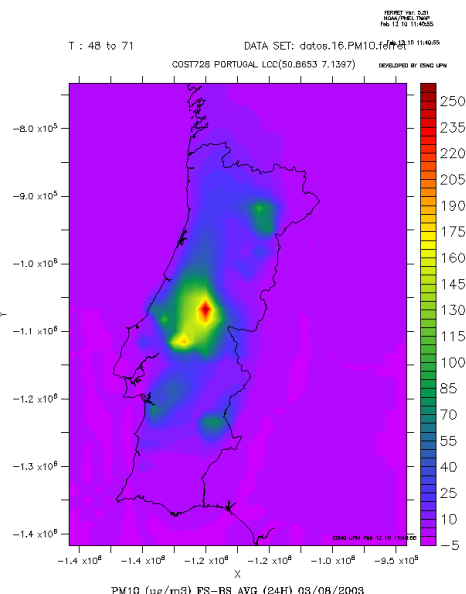

MM5-CMAQ

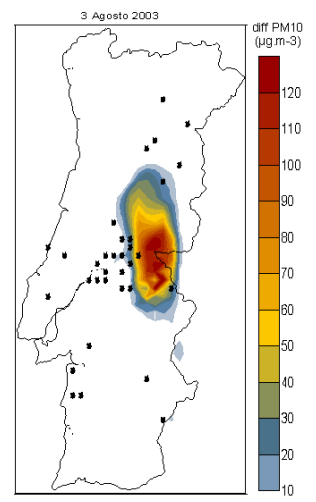

MM5-CHIMERE

Figure 4: $\quad$ Spatial differences $\left(\mu \mathrm{g} . \mathrm{m}^{-3}\right)$ between simulation results with (FS) and without (BS) forest fire emissions, for PM10 daily averages on August $3^{\text {rd }}, 2003$. 


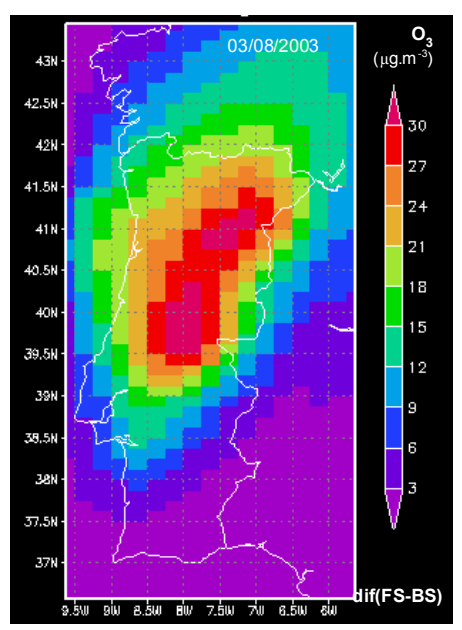

LOTOS-EUROS

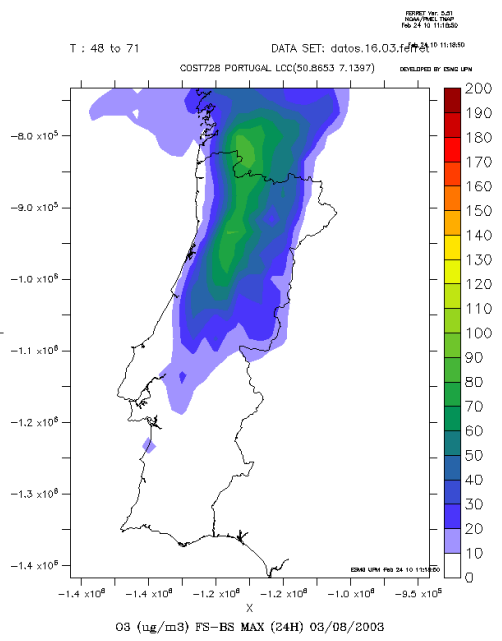

$\mathrm{WRF} / \mathrm{chem}$

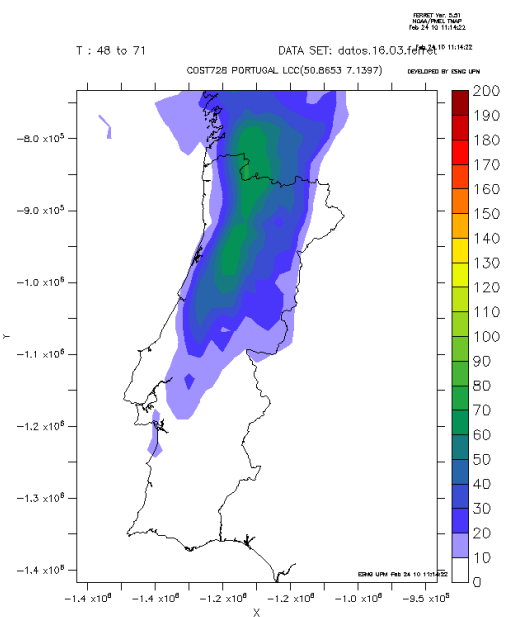

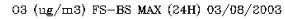

\section{MM5-CMAQ}

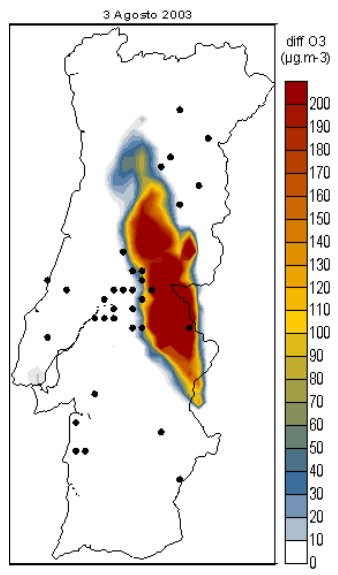

MM5-CHIMERE

Figure 5: $\quad$ Spatial differences $\left(\mu \mathrm{g} . \mathrm{m}^{-3}\right)$ between simulation results with (FS) and without (BS) forest fire emissions, for $\mathrm{O}_{3}$ daily maximum values on August $3^{\text {rd }}, 2003$.

measurements go upper than the $200 \mu \mathrm{g} . \mathrm{m}^{-3}$ (peak measured values) models were underestimating. The secondary character of ozone is clearly shown when comparing both pollutants series. Fires were spreading near Coimbra city, where the monitoring station is located, at the $3^{\text {rd }}$ day of August and only PM10 measured values show their effects. 
For this specific day, the impact of forest fires was higher at the central inland part of Portugal, and the PM10 daily mean difference reached $300 \mu \mathrm{g} \cdot \mathrm{m}^{-3}$, in case of MM5-CMAQ and WRF/chem. Comparatively, the models present different magnitude of the forest fires impacts, as consequence of run options (meteorological data, chemical mechanism, and others...). The slight deviation of the PM10 "plume" towards East regarding MM5-CHIMERE results could explain the difficulty of this modelling system to capture the measured peak shown in Figure 3.

The spatial analysis of results can contribute to a better understanding of the simulated values. Figures 4 and 5 show the spatial difference between both simulations (FS-BS) results, for this critical day (2003 August 3), concerning daily values for PM10 and maximum values for $\mathrm{O}_{3}$, respectively.

The spatial differences for $\mathrm{O}_{3}$ (Figure 5), as expected, are very different from the ones shown in Figure 4 for PM10. The forest fire emission affected a larger area of Portugal with the photochemical "plume" going to the North. MM5CMAQ and WRF/chem even simulated a consumption of ozone in the central part of Portugal where fires were spreading and emitting nitrogen oxides.

\section{Conclusions}

This work investigated the impacts of forest fire emissions on the air quality over Portugal. The numerical modelling approach applied in this work confirms the significant impact of forest fire on atmospheric pollutants concentrations. In general, the different modelling systems show a good performance, which improves when forest fire emissions are considered, particularly for the PM10 concentrations. On the other hand, the influence of the forest fire emissions in $\mathrm{O}_{3}$ formation is not evident and needs more attention. Future work will require that several questions should be analysed and integrated regarding the photochemical effects, namely the decrease in photolysis rates and increase in atmospheric radiative properties.

The evaluation of the impact of forest fires on the air quality should be included in air quality assessment procedures, specifically in areas that are often affected by forest fires as south Europe, and air quality modelling systems can be important tools to achieve this goal.

\section{Acknowledgements}

The authors thank the Portuguese Foundation for Science and Technology for the $\mathrm{PhD}$ grant of V. Martins (SFRH/BD/39799/2007) and for the Projects INTERFACE (POCI/AMB/60660/2004) and FUMEXP (PTDC/AMB/ 66707/2006) under the scope of the POCI2010 program and the European FEDER funds. In addition, COST 728 is acknowledged. 


\section{References}

[1] Miranda, A.I., Coutinho, M., and Borrego, C. Forest fires emissions in Portugal: a contribution to global warming? Environmental Pollution 83, 121-123, 1994.

[2] Simmonds, P.G., Manning, A.J., Derwent, R.G., Ciais, P., Ramonet, M., Kazan, V. and Ryall, D. A burning question. Can recent growth rate anomalies in the greenhouse gases be attributed to large-scale biomass burning events? Atmospheric Environment 39, 2513-2517, 2005.

[3] Miranda, A.I., Borrego, C., Martins, H., Martins, V., Amorim, J. H., Valente, J. and, Carvalho, A. Forest Fire Emissions and Air Pollution in Southern Europe in: Earth Observation of Wildland Fires in Mediterranean Ecosystems. Springer. Berlin. 171-187, 2009.

[4] Coghlan B. The human health impact of the 2001-2002 "Black Christmas" bushfires in New South Wales, Australia: an alternative multidisciplinary strategy. Journal of Rural and Remote Environmental Health, 3(1), pp. 18 28, 2004.

[5] Hodzic, A., Madronich, S., Bohn, B., Massie, S., Menut, L., and Wiedinmyer, C. Wildfire particulate matter in Europe during summer 2003: meso-scale modelling of smoke emissions, transport and radiative effects. Atmos. Chem. Phys. Discuss., 7, 4705 - 4760, 2007.

[6] Sofiev, M., Vankevich, R., Lotjonen, M., Prank, M., Petukhov, V., Ermakova, T., Koskinen, J., Kukkonen J. An operational system for the assimilation of the satellite information on wild-land fires for the needs of air quality modelling and forecasting. Atmos. Chem. Phys., 9, 6833-6847, 2009.

[7] Ottmar, R., Miranda, A.I., Sandberg, D. Characterizing Sources of Emissions from Wildland Fires. In Wild land fires and air pollution. Developments in Environmental Science, Vol 8, Chapter 3. Elsevier B.V.: A. Bytnerowicz, M. Arbaugh, A. Riebau and C. Andersen, p.101-136, 2009.

[8] Dudhia J. A nonhydrostatic version of the Penn State / NCAR mesoscale model: Validation tests and simulations of an Atlantic cyclone and cold front. Mon Weather Rev, 121, 1493-513, 1993.

[9] Grell GA, Dudhia J, Stauffer DR. A description of the fifth-generation Pennstate/NCAR mesoscale model (MM5). NCAR/TN- 398+ STR. NCAR Technical Note, 1994.

[10] Byun, DW, Young, J, Gipson, G, Godowitch, J, Binkowski, F, Roselle, S, et al. Description of the Model-3 Community Multiscale Air Quality (CMAQ) model. Proceedings of the American Meteorological Society 78th Annual Meeting, Phoenix, AZ; 1998. p. 264-8. Jan 11-16, 1998.

[11] San José R, Pérez JL, González RM. A mesoscale study of the impact of industrial emissions by using the MM5-CMAQ modelling system. International Journal of Environment and Pollution. 22 (1/2), 144-162, 2004. 
82 Modelling, Monitoring and Management of Forest Fires II

[12] Monteiro A., Miranda A.I., Borrego C., Vautard R., Ferreira J., Perez A.T. Long-term assessment of particulate matter using CHIMERE model.. Atmospheric Environment. 41, 36, 7726-7738, 2007.

[13] Schaap, M., van Loon, M., ten Brink, H.M., Dentener, F.D., Builtjes, P. Secondary inorganic aerosol simulations for Europe with special attention to nitrate, Atmos. Phys. Chem., 4, 857-874, 2004.

[14] Schaap, M., Timmermans, R.M.A., Sauter, F.J., Roemer, M., Velders, G.J.M., Boersen, G.A.C., Beck J.P., Builtjes, P. The LOTOS-EUROS model: description, validation and latest developments. International Journal of Environment and Pollution, 32(2), 270-290, 2008.

[15] Grell, G., Peckham, R., Schmitz, S., McKeen, G., Frost, W., Skamarock, B. Fully coupled online chemistry within the WRF model, Atmos. Environ., 39, 6957-6975, 2005.

[16] EC - European Commission. San-Miguel-Ayanz, J., Barbosa, P., Camia, A., Kucera, J., and Libertà, G. (Eds), Forest Fires in Europe - 2003 fire campaign -, Official Publication of the European Communities, SPI.04.142.EN, 2004.

[17] Miranda, A.I., Monteiro, A., Martins, V.; Carvalho, A., Schaap, M., Builtjes, P., Borrego, C. Forest fires impact on air quality over Portugal. In Air Pollution Modeling and Its Application XIX, C. Borrego and A.I. Miranda: Dordrecht: Springer, 2008.

[18] Borrego C., Monteiro A., Ferreira J., Miranda A. I., Costa A.M., Carvalho A. C., Lopes M. Procedures for estimation of modelling uncertainty in air quality assessment. Environment International. 34, 613-620, 2008. 